\title{
A comparative study of induction of preterm vaginal delivery at 20 to 28 weeks gestation in previous one lower segment caesarean section by foley catheter and prostaglandin $\mathrm{E}_{2}$ gel
}

\author{
Shruti Agarwal*, Neelam Bharadwaj, Lata Rajoria, Indira Lamba
}

Department of Obstetrics and Gynecology, SMS Medical College, Jaipur, Rajasthan, India

Received: 07 June 2017

Accepted: 29 June 2017

*Correspondence:

Dr. Shruti Agarwal,

E-mail: shrutiagarwal_1212@yahoo.com

Copyright: () the author(s), publisher and licensee Medip Academy. This is an open-access article distributed under the terms of the Creative Commons Attribution Non-Commercial License, which permits unrestricted non-commercial use, distribution, and reproduction in any medium, provided the original work is properly cited.

\begin{abstract}
Background: The aim of the study to assess the maternal outcome and safety of induced preterm vaginal birth after a previous one lower segment caesarean delivery.

Methods: In this study, 100 women who had singleton pregnancies with a previous one term lower segment caesarean section, in whom induction of labour was required in between 20 to 28 wks of gestation, were included. Group A $(n=50)$ were induced by transcervical foley catheter and group B $(n=50)$ were induced by prostaglandin E2 gel and then progression of labour was monitored. Both groups were compared in terms of induction delivery interval, efficacy and safety.

Results: In our study, all women were delivered vaginally and hysterotomy was not required. The mean induction delivery interval in Foley catheter group $(20.180 \pm 3.3499 \mathrm{hrs})$ was significantly shorter (p-value <0.001) than PGE2 gel group B $(24.050 \pm 3.6537 \mathrm{hrs})$. There was no case of uterine rupture, puerperal pyrexia, postpartum haemorrhage and uterine hyperstimulation.

Conclusions: Women with previous lower segment caesarean section in whom premature induction of labour is required for any reason can be done easily, safely and effectively without maternal morbidity. Induction can be done more effectively by using transcervical foley catheter than intracervical prostaglandin E2 gel. It has shorter induction delivery interval and low complication. Hence, I suggest that every woman with previous one lower segment caesarean section who requires premature induction should go for trial of labour before repeating caesarean section.
\end{abstract}

Keywords: Caesarean, Foley catheter, Induction, Preterm, Prostaglandin $\mathrm{E}_{2}$ gel

\section{INTRODUCTION}

A woman who has had a previous caesarean delivery has two choices to give birth again either by a scheduled caesarean delivery or birth vaginally. This is called a vaginal birth after caesarean delivery (VBAC). A trial of labor after caesarean delivery (TOLAC) is the attempt to have a vaginal birth after caesarean delivery. The dictum, "once caesarean section always caesarean section" no longer holds true. Several studies suggest that in women with prior caesarean section for nonrecurring cause, a trial of labour is safer than elective repeat caesarean section. This tendency to resist caesarean section arose from the wish not to compromise a patient's obstetric future, because the dictum twice a caesarean section always a caesarean section holds true. ${ }^{1}$ There are some obstetric situations where induction of labour is required in previous one caesarean section such as; 
- Intrauterine fetal death,

- Anhydramnios,

- Fetal congenital anomalies

- Preterm premature rupture of membranes.

To avoid hysterotomy and caesarean section and to maintain further better obstetrics outcome induction of premature labour may be required. In the absence of a ripe or a favourable cervix, a successful vaginal delivery is less likely. The cervix is considered to be unfavourable for full term vaginal delivery if the Bishop's score is less than 6 but in cases where induction is required for above reasons, cervix is usually os closed and uneffaced. A common dilemma facing the obstetrician is the induction of labour in the presence of an unfavourable cervix.

Various techniques have been used to ripen the unfavourable cervices, which include pharmacological and non-pharmacological (mechanical) methods. The pharmacological methods include prostaglandins (PGE1, PGE2), oxytocin, oestrogens, mifepristone, etc. ${ }^{2}$ The nonpharmacological methods include a transcervical Foley catheter, bougies, hygroscopic laminaria tents and forewater amniotomy. ${ }^{3}$ Such mechanical methods are advantageous in terms of their re-versibility and the reduced expenditure. ${ }^{4}$

\section{METHODS}

This prospective study was conducted in the Department of Obstetrics and Gynaecology, SMS Medical College, Jaipur from March 2015 to October 2016. Hundred women who were admitted in labour room with a previous one term lower segment caesarean section, in whom induction of labour was required in between 20 to 28 wks of gestation, were selected for the study. Those who had singleton pregnancies with a previous one caesarean section was included.

Inclusion Criteria for this study were women with previous one term lower segment caesarean section (LSCS) with 20 to 28 wks gestation of pregnancy with:

- Intrauterine fetal death,

- Preterm premature rupture of membranes,

- Anhydramnios,

- Fetal congenital anomalies.

Women with any other uterine scar and previous hysterotomy were excluded. A written informed consent was taken from all the cases included in the study. All women evaluated thoroughly regarding complete history, parity, indication for previous LSCS, thorough clinical examination, per-abdominal examination, pelvic examination were done and all risk factors were evaluated.

All cases were divided in two groups alternatively as they admitted. In group A - Foley catheter No. $16 \mathrm{~F}$ method was used to ripen the cervix in 50 cases. In group B Dinoprostone $\mathrm{PGE}_{2}$ gel method was used in 50 cases.

In group A under aseptic conditions, with the patients lying in the lithotomy position, the cervix was assessed through per vaginal examination. A 16 French Foley catheter was inserted into the endocervical canal, beyond the internal os and the balloon was inflated with $30 \mathrm{ml}$ of sterile water. The catheter was strapped to the thigh with gentle traction. Progression of labour was monitored at 6 hours intervals. The catheter was expelled spontaneously and it was checked whether the cervix became favourable or whether a spontaneous rupture of the membranes had occurred. The Artificial Rupture of the Membranes (ARM) was followed by the starting with an intravenous oxytocin infusion of 2.5 units of oxytocin in $500 \mathrm{ml}$ of $5 \%$ dextrose at 10 drops/minute. The dose was titrated till the desired uterine contractions were achieved.

In group $\mathrm{B}$ the $0.5 \mathrm{mg}$ Dinoprostone $\mathrm{PGE}_{2}$ gel in a $3 \mathrm{ml}$ pre-loaded syringe were used. Under aseptic conditions with the woman in lithotomy position, the tip of a prefilled syringe is placed, the gel was deposited intracervically. After application, the woman reclined for at least 10 minutes. The women were assessed for progression of labour at periodic interval of 6 hours. The next dose was repeated after 12 hours if the condition of cervix was not favourable. Maximum 2 doses of Dinoprostone $\mathrm{PGE}_{2}$ gel instilled. ARM was followed by the starting with an oxytocin infusion as described above till desired uterine contractions were achieved.

All women were monitored for cervical ripening, induction delivery interval, mode of delivery (vaginal or hysterotomy) and maternal complications (uterine hypertonicity, uterine rupture and sepsis).

\section{RESULTS}

In the study of 100 cases with gestational age of 20 to 28 wks with previous one lower segment caesarean section in whom induction of labour required, 50 women were induced by using transcervical foley catheter and other 50 women by intracervical prostaglandin $\mathrm{E}_{2}$ gel. Both groups were compared in terms of induction delivery interval, efficacy, and safety.

Table 1 compares different parameters between group A and group B. Both the groups are comparable regarding maternal age, gravida, parity, gestational age. There are various indications for preterm labour induction, intrauterine fetal death was the most common indication. Gravidity also affects mean induction delivery interval. The mean interval of induction to delivery in $2^{\text {nd }}$ gravida women was $21.84 \pm 2.56 \mathrm{hrs}$ and $25.97 \pm 2.41 \mathrm{hrs}$ in group $\mathrm{A}$ and group B respectively and in 3rdgravida women was $17.59 \pm 2.37 \mathrm{hrs}$ in group A and $20.52 \pm 1.88 \mathrm{hrs}$ in group B. P value shows significant difference in results indicate the time taken to deliver in 2nd and 3rdgravida women was significantly less in induction by Foley 
catheter than $\mathrm{PGE}_{2}$ gel. The mean interval of induction to deliver in 4th gravida women was $14.38 \pm 0.53 \mathrm{hrs}$ and $17.58 \pm 1.94$ hrs in group A and group B respectively. P value 0.118 which was non- significant which may be due to very less no. of 4 th gravida women. $3^{\text {rd }}$ and $4^{\text {th }}$ gravida women considered having one and two previous vaginal delivery respectively along with one lower segment caesarean section (Table 1).

Table 1: Characteristics of women.

\begin{tabular}{|llll|}
\hline Parameters & Group A & Group B & P value \\
\hline Mean Age & $24.72 \pm 2.86$ years & $25.76 \pm 3.12$ years & $0.89 \mathrm{NS}$ \\
\hline Mean gravid & $2.40 \pm 0.57$ & $2.34 \pm 0.59$ & $0.61 \mathrm{NS}$ \\
\hline Mean parity & $1.4 \pm 0.57$ & $1.34 \pm 0.59$ & $0.61 \mathrm{NS}$ \\
\hline Gestational Age & $24.16 \pm 2.61$ week & $24.06 \pm 2.60$ week & $1.00 \mathrm{NS}$ \\
\hline Indication of induction & \multicolumn{3}{l}{} \\
\hline Intrauterine fetal death & 17 & 19 \\
\hline Preterm premature rupture of membranes & 15 & 5 \\
\hline Anhydramnios & 4 & 13 \\
\hline Fetal congenital anomalies & 14 & & \\
\hline Gravida with induction delivery interval & \multicolumn{3}{l}{} \\
\hline G2 & $(\mathrm{N}=32) 21.84 \pm 2.56 \mathrm{hr}$ & $(\mathrm{N}=34) 25.97 \pm 2.41 \mathrm{hr}$ & $<0.001 \mathrm{~S}$ \\
\hline G3 & $(\mathrm{N}=16) 17.59 \pm 2.37 \mathrm{hr}$ & $(\mathrm{N}=13) 20.52 \pm 1.88 \mathrm{hr}$ & $0.001 \mathrm{~S}$ \\
\hline G4 & $(\mathrm{N}=2) 14.38 \pm 0.53 \mathrm{hr}$ & $(\mathrm{N}=3) 17.58 \pm 1.94 \mathrm{hr}$ & $0.118 \mathrm{NS}$ \\
\hline
\end{tabular}

The mean induction delivery interval of this study was $22.11 \pm 3.9 \mathrm{hrs}$. Whereas in group A was $20.18 \pm 3.34 \mathrm{hrs}$ and in group B was $24.05 \pm 3.65 \mathrm{hrs}$. P value is $<0.001$ shows significant difference. This table indicate induction to delivery interval is shorter when induction done by Foley catheter than $\mathrm{PGE}_{2}$ gel (Table 2).

Table 2: Mean induction delivery interval $(\mathrm{Hr})$.

\begin{tabular}{|llll|}
\hline Group & N & Mean \pm Std & P value LS \\
\hline Group A & 50 & $20.18 \pm 3.3499$ & \\
Group B & 50 & $24.05 \pm 3.6537$ & $<0.001 S$ \\
Total & 100 & $22.115 \pm 3.993$ & \\
\hline
\end{tabular}

No. of women delivered within $24 \mathrm{hrs}$ in group A were $84 \%$ and $50 \%$ in group B.

After $24 \mathrm{hrs}$, no. of delivered women were $16 \%$ and $50 \%$ in group $\mathrm{A}$ and group $\mathrm{B}$ respectively. $(\mathrm{P}=<0.001)$. Signifies more women delivered in shorter time by using Foley catheter than $\mathrm{PGE}_{2}$ gel (Table 3).

Table 3: Distribution of the cases according to induction delivery interval.

\begin{tabular}{|llllll|}
\hline & \multicolumn{2}{l}{ Group-A } & \multicolumn{2}{c|}{ Group-B } \\
\hline $\begin{array}{l}\text { Induction } \\
\text { delivery } \\
\text { interval (Hr) }\end{array}$ & No. & $\%$ & No. & $\%$ & $\begin{array}{l}\text { Notal } \\
\text { No. }\end{array}$ \\
\hline$<24$ & 42 & 84 & 25 & 50 & 67 \\
\hline$\geq 24$ & 8 & 16 & 25 & 50 & 33 \\
\hline Total & 50 & 100 & 50 & 100 & 100 \\
\hline
\end{tabular}

Chi-square $=11.578$ with 1 degree of freedom; $\mathrm{P}=<0.001$
There were no cases of uterine rupture, puerperal pyrexia, postpartum haemorrhage, uterine hyperstimulation.

\section{DISCUSSION}

In the last 3 decades, the rate of caesarean deliveries has been rising continuously worldwide and has reached $>30 \%$ in many countries. A major contributor to this trend is the concomitant decline in the percentage of trial of labor after caesarean delivery (TOLAC) and vaginal birth after caesarean delivery (VBAC). The alternative for TOLAC is to perform an elective repeat caesarean delivery (ERC). ERC can be associated with risks of short-term and longer term maternal complications. ${ }^{5}$

The unripe cervix is a major impediment to the success of labour induction and vaginal delivery. The goal of labour induction is to achieve vaginal delivery by ripening the cervix and stimulating uterine contractions before the spontaneous onset of labour. The externally administered prostaglandins are effective in ripening the cervix and hasten the delivery, but they increase the risk of the uterine hyperstimulation. ${ }^{3}$ The mechanical methods stimulate the endogenous prostaglandin production, thus ripening the cervix. ${ }^{4}$

The mean time interval of induction to delivery of foley catheter (group A) was 20.18 $\pm 3.34 \mathrm{hrs}$. Whereas in prostaglandin $\mathrm{E}_{2}$ (group B) was $24.05 \pm 3.65 \mathrm{hrs}$. Induction to delivery interval is significantly shorter when induction done by Foley catheter than $\mathrm{PGE}_{2}$ gel. In similar study done by Farah Ziyauddin et al in seventy women with singleton pregnancies at term, with previous one lower segment caesarean section and by Yossi 
Mizrachi et al on 346 nulliparous women resulted that the induction to the delivery interval was shorter with the Foley catheter as compared to the $\mathrm{PGE}_{2}$ gel., ${ }^{4,6}$

Induction of labour in previous one caesarean section offers distinct advantages over a repeat caesarean section since the operative morbidity and mortality are completely eliminated, the hospital stay is much shorter and expenses involved are much less. The rate of caesarean section needs to be reduced by resorting to a trial of vaginal delivery after previous caesarean section.

Compared with a planned caesarean delivery, a successful TOLAC is associated with the multiple benefits such as no abdominal surgery, shorter recovery period, lower risk of infection, less blood loss. If women desire to have more children, VBAC may help her to avoid problems linked to multiple caesarean deliveries. These problems include hysterectomy, bowel or bladder injury and certain problems with the placenta. ${ }^{7}$

In this study, all 100 women with previous lower segment caesarean section on preterm induction delivered vaginally successfully, no women needed hysterotomy and there was no other complication. Both the modes of induction in women with previous one caesarean section is safe, simple and effective.

No. of women delivered within $24 \mathrm{hrs}$ in group A was $84 \%$ (42 out of 50 women) and $50 \%$ (25 out of 50 women) in group B. By using foley catheter significant no. of women delivered within $24 \mathrm{hrs}$. It always creates a big mental trauma to the women and her family members, as they come to know the bad status of their baby in utero and requirement of preterm delivery. In this condition, after taking decision, they want to deliver the baby as earliest without increasing mother's morbidity.

The objective of our study is to assess the maternal outcome and safety of induced preterm vaginal birth after a previous one lower segment caesarean delivery. To assess the safety of preterm vaginal birth in previous one lower segment caesarean section and to reduce the risk of recurrent caesarean section and associated maternal morbidity.

Women with one or more previous vaginal delivery, particularly previous VBAC, is the single best predictor of successful VBAC and is associated with a planned VBAC success rate of $85-90 \%$. Previous vaginal delivery is also independently associated with a reduced risk of uterine rupture $(\mathrm{C}) .^{8}$ With the induction of labour in a previous caesarean section, the uterine rupture can be a serious complication.

In this study, there was no case of uterine rupture, puerperal pyrexia, postpartum haemorrhage, uterine hyperstimulation or any other complication. Similar studies done by Marta jozwiak et al and Farah Ziyauddin et al also found less complication during induction with mechanical method in previous one caesarean section. ${ }^{4,9}$

Planned preterm VBAC has similar success rates to planned term VBAC but with a lower risk of uterine rupture (B). ${ }^{8}$ Induction of labour using mechanical methods (amniotomy or Foley catheter) is associated with a lower risk of scar rupture compared with induction using prostaglandins (D). ${ }^{8}$ The induction by using Foley catheter mimic the physiology of the labour onset more closely, resulting in a less likelihood of hyperstimulation and postpartum haemorrhage as compare to prostaglandin $\mathrm{E}_{2}$ gel. ${ }^{4}$

Marta jozwiak et al studied induction of labour with a Foley catheter in 208 women with an unfavorable cervix and a history of one CS. ${ }^{9}$ Of the women $60 \%$ had a spontaneous vaginal delivery and $11 \%$ were delivered by vacuum extraction and concluded that induction of labor with a transcervical Foley catheter is an effective method to achieve vaginal delivery in women with a previous caesarean delivery. There is a low risk of uterine rupture and maternal and neonatal (infectious) morbidity in this cohort.

According to study done by Farah Ziyauddin et al there is no case of uterine rupture or scar dehiscence. ${ }^{4}$ Uterine hypertonicity and tachysystole were seen in the cases which were induced by using the $\mathrm{PGE}_{2}$ gel. Few cases had mild atonic PPH which was unrelated to mode of induction.

\section{CONCLUSION}

To conclude, women with previous lower segment caesarean section in whom premature induction of labour is required for any reason can be done easily, safely and effectively without maternal morbidity. Induction can be done more effectively by using transcervical Foley catheter than prostaglandin E2 gel. It has shorter induction delivery interval and low complication. Better result is seen in women who have had a vaginal delivery along with one previous lower segment caesarean section. Hence, suggest that every woman with previous one lower segment caesarean section who requires premature induction should go for trial of labour before repeating caesarean section.

\section{ACKNOWLEDGMENTS}

Authors would like to thank Dr. Neelam Bharadwaj and Dr. Lata Rajoria, Department of Obs and Gynae, SMS Medical College, Jaipur, Rajasthan for their help, advise and permitting to carry out this study and most importantly the clients to let us conduct this study.

\section{Funding: No funding sources}

Conflict of interest: None declared

Ethical approval: The study was approved by the Institutional Ethics Committee 


\section{REFERENCES}

1. Jani R, Munshi D. Management of pregnancy with previous lower segment caesarean section in Modern obstetric practice. NHL J Med Sci. 2013;2(2):59-63.

2. Dutta DC "Textbook of obstetrics" $7^{\text {th }}$ edition; 2011;34:522-31.

3. Kelly AJ, Malik S, Smith L, Kavanagh J, Thomas J. "Vaginal prostaglandin (PGE2 and PGF2 $\alpha$ ) for induction of labour at term". Cochrane Database Syst Rev. 2009;4:CD003101.

4. Ziyauddin F, Hakim S, Beriwal S. The transcervical foley catheter versus the vaginal prostaglandin e2 gel in the induction of labour in a previous one caesarean section-a clinical study. JCDR. 2013;7(1):140.

5. Jastrow N, Demers S, Chaillet N. Lower uterine segment thickness to prevent uterine rupture and adverse perinatal outcomes: a multicenter prospective study. Am J Obstet Gynecol. 2016;215(5):604.e1-604.e6.

6. Mizrachi Y, Levy M, Bar J, Kovo M. Induction of labor in nulliparous women with unfavorable cervix: a comparison of Foley catheter and vaginal prostaglandin E2. Arch Gynecol Obstet. 2016;294(4):725-30.

7. American College of Obstetricians and Gynaecologists: Vaginal birth after previous caesarean delivery; 2011.

8. RCOG guidelines. Birth After Previous Caesarean Birth Green-top Guideline; 2015:45.

9. Jozwiak M, Hilde A, Van De Lest, Burger B, Marja GK, Dijksterhuis and Jan Willem De Leeuw. Cervical ripening with Foley catheter for induction of labor after caesarean section: a cohort study. Acta Obstet Gynecol Scand. 2014;93(3):296-301.

Cite this article as: Agarwal S, Bharadwaj N, Rajoria L, Lamba I. A comparative study of induction of preterm vaginal delivery at 20 to 28 weeks gestation in previous one lower segment caesarean section by foley catheter and prostaglandin $\mathrm{E}_{2}$ gel. Int J Reprod Contracept Obstet Gynecol 2017;6:3581-5. 